\title{
Analisis Sentimen Review Restoran menggunakan Algoritma Naive Bayes berbasis Particle Swarm Optimization
}

\author{
Retno Sari \\ STMIK Nusa Mandiri Jakarta \\ e-mail: retno.rnr@nusamandiri.ac.id
}

\begin{abstract}
Abstrak
Terdapatnya aplikasi yang memudahkan untuk mengetahui ulasan dari suatu tempat atau makanan membuat pembaca dengan mudah menentukan tempat untuk mereka berwisata kuliner. Ulasan yang diberikan terdiri dari ulasan positif dan ulasan negatif. Algoritma Naive Bayes berbasis Particle Swarm optimization dilakukan untuk mengetahui apakah terdapat peningkatan akurasi. Dataset yang digunakan berupa review restoran yang dibagi menjadi 2 class yaitu class positif dan class negatif, data diujikan menggunakan 10 Fold Cross Validation. Analisis sentimen review restoran menggunakan Algoritma Naive Bayes berbasis Particle Swarm Optimization menghasilkan akurasi sebesar $82.45 \%$. Hasil ini lebih baik dibandingkan dengan menggunakan algoritma Naive Bayes saja yang menghasilkan akurasi sebesar $74.34 \%$.
\end{abstract}

Kata Kunci: analisis sentimen, review restoran, naive bayes, Particle Swarm Optimization.

\section{Abstract}

The existence of an application that makes it easy to find out reviews from a place or food makes the reader easily determine the place for their culinary tour. The reviews provided consist of positive reviews and negative reviews. The Naive Bayes algorithm based on Particle Swarm optimization is done to find out whether there is an increase in accuracy. The dataset used is a restaurant review which is divided into 2 classes, positive class and negative class, the data is tested using 10 Fold Cross Validation. Sentiment analysis of restaurant reviews using Particle Swarm Optimization based on Naive Bayes Algorithm resulted in an accuracy of $82.45 \%$. This result is better than using the Naive Bayes algorithm which produces an accuracy of $74.34 \%$.

Keywords: sentiment analysis, restaurant review, Naive Bayes, Particle Swarm Optimization

\section{Pendahuluan}

Terdapatnya aplikasi yang memudahkan para pecinta kuliner untuk mencari lokasi dan makanan yang sesuai harapan, membuat pecinta kuliner dengan mudah menemukan tempat dan makanan yang diinginkan dimanapun mereka berada. Aplikasi yang ada menyediakan foto, lokasi, ulasan konsumen dan rating yang diberikan oleh konsumen.

Review dan rating yang diberikan membantu pelanggan lain untuk mengevaluasi usaha atau servis yang di berikan dan mereka dapat menentukan pilihan (Govindarajan, 2014).

Klasifikasi sentimen bertujuan untuk mengatasi masalah ini dengan cara otomatis mengklasifikasikan ulasan pengguna menjadi pendapat positif atau negatif (Zhang, Ye, Zhang, \& Yijun, 2011).

Terdapat beberapa penelitian sebelumnya mengenai review restauran diantarannya, penelitian yang dilakukan oleh Zhang, dkk pada tahun 2011 dengan judul klasifikasi sentimen pada review restoran di internet yang di tulis dalam bahasa Canton menggunakan pengklasifikasi Naive Bayes dan Support Vector Machine (Zhang, Ye, Zhang, \& Yijun, 2011). Penelitian yang dilakukan oleh Muthia pada tahun 2017 dengan judul analisis sentimen pada review restoran dengan teks bahasa Indonesia menggunakan algoritma Naive Bayes (Muthia, 2017).

Penelitian yang dilakukan oleh Zhang, dkk pada penelitiannya 
menggunakan fitur bigrams( 2 suku kata) dan trigrams(3 suku kata), pada penelitian ini lebih baik menggunakan fitur bigrams dibandingkan dengan fitur unigrams dan trigrams dan algoritma naive bayes lebih baik dibandingkan dengan SVM (Zhang, Ye, Zhang, \& Yijun, 2011).

Muthia meneliti di menggunakan penggabungan metode pemilihan fitur Genetic Algorithm dengan menggunakan fitur trigram (3 suku kata) mengalami peningkatan akurasi klasifikasi mencapai $4 \%$ dibandingkan sebelum menggunakan metode pemilihan fitur (Muthia, 2017).

Bayes merupakan salah satu klasifikasi probabilistik yang sederhana yang didasarkan pada teorema Bayes dengan asumsi naives yang kuat (Ahmed, Guan, \& Chung, 2014). Keuntungan dari klasifikasi Bayes yaitu bahwa Naive Bayes hanya membutuhkan jumlah yang kecil uuntuk data training untuk memperkirakan parameter yang dibutuhkan untuk klasifikasi (Korada, Kumar, \& Deekshitulu, 2012).Namun Naive Bayes memiliki kekurangan yaitu sangat sensitif dalam pemilihan fitur (Chen, Tian, \& Qu, 2009).

PSO merupakan teknik optimasi yang sangat mudah diterapkan dan terdapat beberapa parameter untuk dimodifikasi (Basari, Hussin, Ananta, \& Zeniarja, 2012).

Pada penelitian ini untuk mengetahui seberapa pengaruhnya Particle Swarm Optimization pada algoritma Naive Bayes untuk analisis sentimen review restoran dalam meningkatkan akurasi.

Tujuan penelitian ini menggunakan

Particle Swarm Optimization dalam meningkatkan akurasi pada analisis sentimen review restoran menggunakan algoritma Naive Bayes.

\section{Metode Penelitian}

Metode penelitian yang penulis lakukan adalah metode eksperimen, dengan tahapan berikut:

a. Pengumpulan Data

Pengumpulan data menggunakan data review restoran yang didapat dari web yelp yang terdiri dari 100 review positif dan 100 review negatif.

b. Pengolahan Data

Dataset ini dalam tahap preprocessing harus melalui 3 proses, yaitu:
a) Tokenization

Pada proses ini, kata yang memiliki tanda baca dan symbol yang bukan huruf dihilangkan.

b) Filter Stopword

Proses penghapusan atau pembuangan kata-kata yang sering ditampilkan dalam dokumen.

c) Stemming

Proses pembuangan prefix dan suffix sehingga membentuk menjadi kata dasar.

c. Metode yang diusulkan

Untuk mengetahui pengaruh pengklasifikasi Naive Bayes berbasis Particle Swarm Optimization dalam analisis sentimen review restoran. Model yang diusulkan pada penelitian ini dapat dilihat dari gambar 1 .

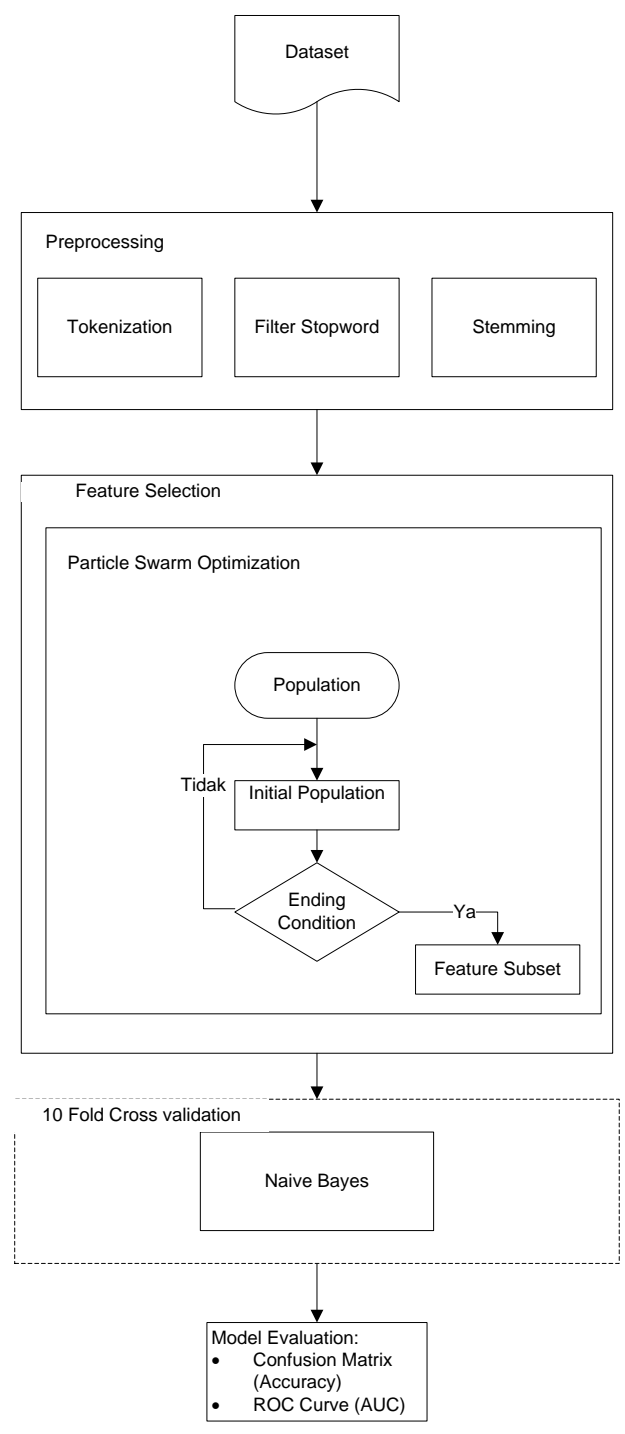

Gambar 1. Model yang di usulkan Sumber: Sari (2018) 
1) Algoritma Naive Bayes

Bayesian klasifikasi adalah pengklasifikasi statistik yang dapat digunakan untuk memprediksi probabilitas keanggotaan suatu class. Bayesian classification didasarkan pada teorema bayes yang memiliki kemampuan klasifikasi serupa dengan Decision Tree dan Neural Network. Bayesian Classification terbukti memiliki akurasi dan kecepatan yang tinggi saat diaplikasikan kedalam database dengan data yang besar (Kusrini \& Luthfi, 2009).

Tahapan dalam algoritma Naive Bayes, sebagai berikut (Han \& Kamber, 2006):

a) Perhatikan $\mathrm{D}$ adalah record training dan ditetapkan labellabel kelasnya dan

b) masing-masing record dinyatakan $\mathrm{n}$ atribut ( $\mathrm{n}$ field) $\mathrm{X}$ $=(\mathrm{X} 1, \mathrm{X} 2, \ldots, \mathrm{Xn})$

c) Misalkan terdapat $m$ kelas $\mathrm{C} 1$, $\mathrm{C} 2, \ldots, \mathrm{Cm}$

d) Klasifikasi adalah diperoleh maximum posteriori yaitu maximum $\mathrm{P}(\mathrm{Ci} \mid \mathrm{X})$

e) Ini diperoleh dari teorema Bayes

$$
P(C i \mid X)=P\left(X \mid C_{i}\right) P(C i) P(X) \ldots \ldots .(2.1)
$$

Karena $P(X)$ adalah konstan untuk semua kelas, hanya perlu dimaksimumkan

$P(C i \mid X)=P(X \mid C i) P(C i)$

2) Particle Swarm Optimization (PSO) Particle Swarm Optimization merupakan sebuah evolusi algoritma yang efisien. Particle Swarm Optimization adalah populasi berdasarkan metode optimasi stokastik berbasis populasi yang didasarkan pada perilaku burung flok. Particle Swarm optimization dimulai dengan satu set acak dan mencapai optima global dengan memperbaharui generasinya (Gupta, Reddy, Shweta, \& Ekbal, 2015). d. Eksperimen dan Pengujian Metode Proses eksperimen pada penelitian ini menggunakan RapidMiner 5.3 untuk pengujian model dilakukan dengan menggunakan dataset. Tahapan pengujian untuk analisis sentimen review restoran sebagai berikut:

1) Menyiapakan dataset untuk eksperimen yang sudah diketahui classnya

2) Mendesain arsitektur algoritma Naïve Bayes pada analisis sentimen review restoran dan mendesain arsitektur menggunakan Particle Swarm Optimization untuk optimasi pada algoritma Naïve Bayes pada analisis sentimen review restoran

3) Melakukan training dan testing terhadap metode Naïve Bayes dan penggunaan algoritma Naive Bayes berbasis Particle Swarm Optimization .

e. Evaluasi dan Validasi Data

Validasi dilakukan menggunakan 10 fold cross validation. Dimana dengan menggunakan teknik ini dengan membagi secara acak ke dalam tiap bagian dimana terdiri dari 10 bagian an setiap bagian akan dilakukan proses klasifikasi. Sedangkan pengukuran akurasi diukur dengan confusion matrix dan kurva ROC (Receiver Operating Characteristics) untuk mengukur nilai AUC.

Tabel 1 Confusion Matrix

\begin{tabular}{|c|c|c|c|}
\hline Classification & \multicolumn{3}{|c|}{ Predicted Class } \\
\hline $\begin{array}{c}\text { Observed } \\
\text { Class }\end{array}$ & & $\begin{array}{c}\text { Class }= \\
\text { Yes }\end{array}$ & Class=No \\
\cline { 2 - 4 } & Class & a (True & b (False \\
& $=$ Yes & Positive & Negative \\
& & - TP) & - FN) \\
\cline { 2 - 4 } & Class & c (False & d (True \\
& $=$ No & Positive & Negative \\
& & - FP) & -TFN) \\
\hline \multicolumn{4}{|c|}{ Sumber : (Gorunescy, 2011) }
\end{tabular}

\section{Hasil dan Pembahasan}

3.1. Hasil

Data yang digunakan dalam pengklasifikasiaan teks terdiri dari 100 review positif dan 100 review negatif. Sebelum diklasifikasikan, data tersebut harus melewati beberapa tahapan proses agar dapat diklasidikasikan ke proses 
selanjutnya, berikut ini adalah tahapan prosesnya:

1) Pengumpulan data

Data review restoran positif dijadikan didalam satu folder dengan nama review positif dan data review restoran negatif dijadikan didalam satu folder dengan nama negatif.

2) Pengolahan Awal Data

Proses pengolahan awal data terdiri dari tokenization, filter stopword dan steeming.

3) Klasifikasi

Dalam proses ini review restoran diklasifikasikan untuk menentukan class untuk setiap reviewnya, class review restoran terbagi dua yaitu class positif dan class negatif. Penentuan class untuk setiap review ditentukan melalui perhitungan probabilitas dari rumus algoritma Naive Bayes.

Data yang diujikan menggunakan 10 fold cross validation. Dimana dengan menggunakan teknik ini dengan membagi secara acak ke dalam tiap bagian dimana terdiri dari 10 bagian an setiap bagian akan dilakukan proses klasifikasi.

\subsection{Pembahasan}

Model klasifikasi teks pada review restoran membuat pembaca dapat dengan mudah mengidentifikasi mana review yang yang postif dan negatif. kata-kata dipisahkan lalu diberikan bobot pada masing-masing kata untuk review restoran yang sudah ada. Kata yang ada dilihat dari hubungan dengan sentimen yang sering muncul dan memiliki bobot paling tinggi untuk setiap dokumennya. Dengan demikian dapat diketahui review tersebut positif atau negatif.

Hasil pengujian model ini dibahas melalui confusion matrix yang menunjukkan seberapa baik model yang terbentuk. pengujian dengan menggunakan algoritma Naive Bayes memiliki akurasi $74.34 \%$. Akurasi tersebut masih perlu ditingkatkan. PSO ditambahkan pada algoritma Naive Bayes untuk analisis sentimen review restoran dan akurasi meningkat menjadi $82.45 \%$.

Dengan menggunakan algoritma Naive Bayes saja menghasilkan akurasi sebesar $74.34 \%$ dan nilai AUC 0.985. Confusion matrix algoritma Naive Bayes sebelum menambahkan PSO.
Tabel 2 Confusion Matrix Algoritma Naive Bayes

\begin{tabular}{|c|c|c|}
\hline \multicolumn{3}{|c|}{ Accuracy : $74.34 \%+/-10.67 \%$ (mikro: } \\
\hline & True negatif & True Positif \\
\hline Pred Negatif & 97 & 48 \\
\hline Pred Positif & 3 & 51 \\
\hline \multicolumn{3}{|c|}{ Sumber : Sari (2018) } \\
\hline
\end{tabular}

Sedangkan algoritma Naive Bayes berbasis Particle Swarm Optimization menghasilkan akurasi sebesar $82.45 \%$ dan nilai AUC 0.993. Confusion matrix algoritma Naive Bayes sesudah menambahkan PSO.

Tabel 3 Confusion Matrix Algoritma Naive Bayes berbasis PSO

\begin{tabular}{|c|c|c|}
\hline \multicolumn{3}{|c|}{ Accuracy : $82.45 \%+/-10.51 \%$ (mikro: } \\
$82.41 \%$ )
\end{tabular}

Sumber : Sari (2018)

Data uji diatas akan dinilai hasil prediksi dengan menggunakan grafik ROC. Berikut grafik ROC untuk algoritma Naive Bayes yang dapat dilihat pada gambar 2. Dan grafik ROC untuk algoritma Niave Bayes berbasis Particle Swarm Optimization dapat dilihat pada gambar 3

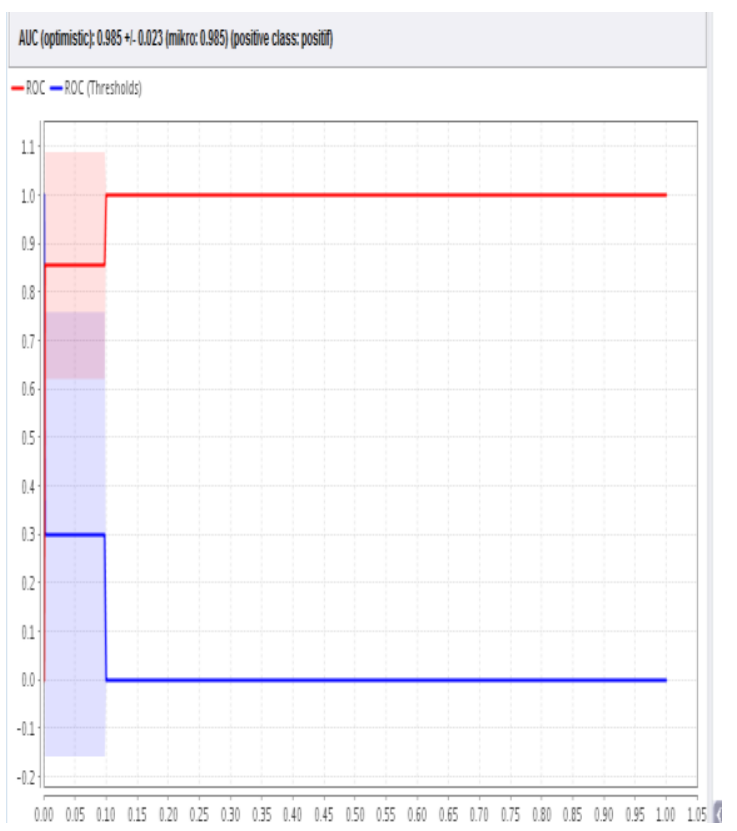

Gambar 2. Kurva ROC model Naive Bayes Sumber : Sari (2018) 


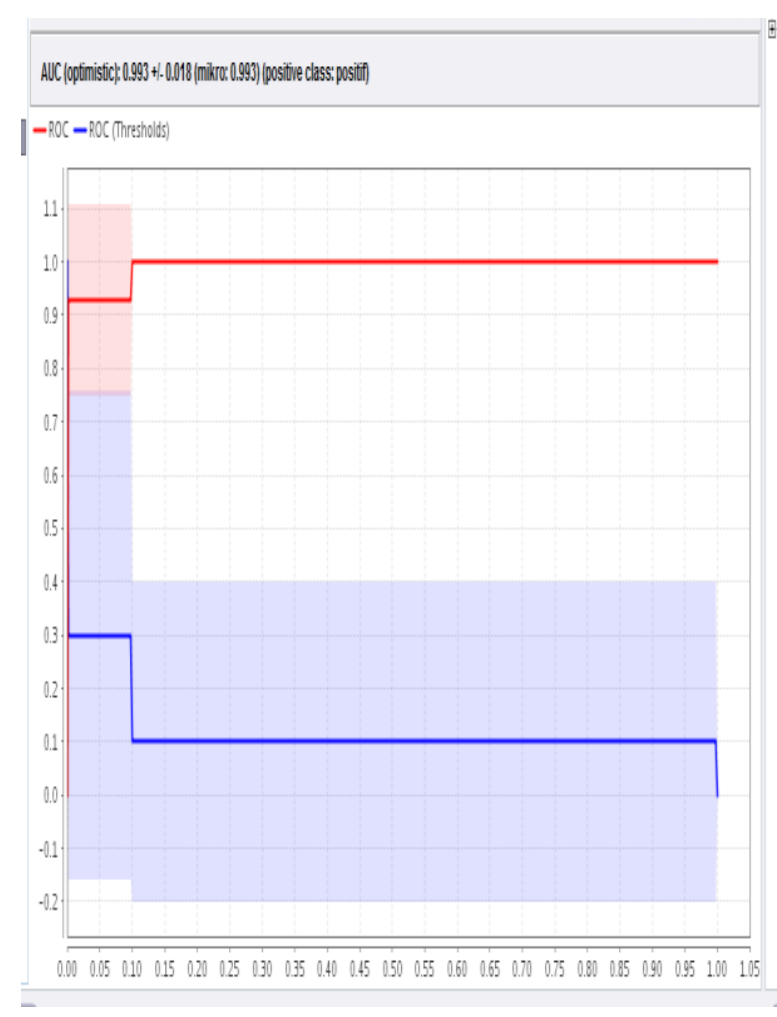

Gambar 3. Kurva ROC model Naive Bayes berbasis PSO

Sumber : Sari (2018)

Berdasarkan seluruh hasil eksperimen dapat disimpulkan bahwa PSO telah dapat meningkatkan kinerja algoritma Naive Bayes pada analisis sentimen review restoran. Perbandingan model algoritma Naive Bayes sebelum dan sesudah menggunakan PSO dapat di lihat pada tabel 4.

Tabel 4 Perbandingan algoritma Naive Bayes sebelum dan sesudah menggunakan PSO

\begin{tabular}{|c|c|c|}
\hline & $\begin{array}{c}\text { Algoritma } \\
\text { Naive Bayes }\end{array}$ & $\begin{array}{c}\text { Algorima } \\
\text { Naive Bayes } \\
+ \text { PSO }\end{array}$ \\
\hline $\begin{array}{c}\text { Review } \\
\text { positif }\end{array}$ & 51 & 66 \\
\hline $\begin{array}{c}\text { Review } \\
\text { Negatif }\end{array}$ & 97 & 98 \\
\hline & $74.34 \%$ & $82.45 \%$ \\
\hline
\end{tabular}

\section{Kesimpulan}

Kesimpulan yang diperoleh setelah melakukan eksperimen untuk memperoleh akurasi yang lebih akurat pada analisis sentimen review restoran menggunakan algoritma Naive Bayes berbasis Particle
Swarm memiliki akurasi sebesar $82.45 \%$, sedangkan analsis sentimen review restoran dengan menggunakan algoritma Naive Bayes didapatkan akurasi sebesar $74.34 \%$.

Dapat dilihat dari hasil eksperimen algoritma Naive Bayes berbasis Particle Swarm Optimization terjadi peningkatan yang sangat signifikan, peningkatkan akurasi mencapai $8.11 \%$.

\section{Referensi}

Ahmed, I., Guan, D., \& Chung, T. (2014). SMS Classification based on Naive Bayes classifier and Apriori Alhoritm Frequent Itemset. International Journal of Machine Learning and Computing Vol 4 No 2.

Basari, A. S., Hussin, B., Ananta, I. G., \& Zeniarja, J. (2012). Opinion Mining of Movie Revie using Hybrid Method of SUpport Vector Machine and Particle Swarm Optimization. Malaysian Technical Universities Conference on Engineering \& Technology 2012,MUCET 2012 (hal. 453-462). Malaysia: Elsevier.

Chen, J. H., Tian, S., \& Qu, Y. (2009). Feature Selection for text classification with Naive Bayes. Expert Systems with Application 36 (3), 5432-5435.

Gorunescy, F. (2011). Data Mining Concept Model Technique. Verlag Berlin Heidelberg: Springer.

Govindarajan, M. (2014). Sentimen Analysisi of Restaurant Review Using Hybrid Classification. 2nd IRF International Conference. India.

Gupta, D. K., Reddy, K. S., Shweta, \& Ekbal, A. (2015). PSO-ASent: Feature Selection Using Particle Swarm Optimization for Aspect Based Sentiment Analysis. Natural Language Processing and Information Systems Volume 91(1) (hal. 220-233). Switzerland: Springer International.

Han, J., \& Kamber, M. (2006). Data Mining Concepts and Techniques. San Francisco: Elsevire.

Korada, N., Kumar, N., \& Deekshitulu, Y. (2012). Implementation of Naive Bayesian Classifier and Ada-Boost Algorithm Using Maize Expert 
System. International Journal of Information Sciencesan Techniques.

Kusrini, \& Luthfi, E. (2009). Algoritma Data Mining. Yogyakarta: Andi Offset.

Muthia, D. A. (2017). Analisis Sentimen pada Review Restoran Dengan teks Bahasa Indonesia Menggunakan Algoritma Naive Bayes. Jurnal IImu Pengetahuan dan Teknologi Komputer, 39-45.

Zhang, Z., Ye, Q., Zhang, Z., \& Yijun, L. (2011). Sentiment classification of Internet restaurant reviews written in Cantonese. Expert Systems with Applications, 7674-7682. 